\title{
DeVElopment Of A NeW Application For MULTIMEDIA LEARNING WITH ANIMATION EXAGGERATION BASED ON ADDIE MODEL
}

\author{
Nor Hasbiah Ubaidullah ${ }^{1}$, Aizu Khalili Zohedi ${ }^{1}$ and Norasikin Fabil ${ }^{2}$ \\ ${ }^{1}$ Faculty of Art, Computing \& Creative Industry, Universiti Pendidikan Sultan Idris, \\ Tanjung Malim, Malaysia \\ ${ }^{2}$ Faculty of Science and Technology, Universiti Sains Islam Malaysia, Nilai, Malaysia
}

\begin{abstract}
Several studies have shown that a majority of students have problems in learning the topic of integers of the Form One Mathematics. This study was carried out to develop and testing a multimedia learning application with the principles of animation exaggeration on students' achievement. The experimental study was based on the pre-test postest control group design involving two experimental groups and one control group. The development of the multimedia learning application was based on the ADDIE model. The main data were the mean scores of the pre-test and posttest measurements, and an interview. An analysis of variance (ANOVA) was carried out showing that the group that used the multimedia learning application with the principles of animation exaggeration outperformed the other two groups. This result suggests that exaggeration principles can be used in the development of multimedia learning tools to help students learn mathematics, especially for topics with abstract concepts.
\end{abstract}

\section{KEYWORDS}

Animation exaggeration, Form One Mathematics integers, multimedia learning application.

\section{INTRODUCTION}

In the Malaysian educational system, mathematics is one of the mandatory subjects that students need to learn to achieve a certain mastery level. Nevertheless, a majority of students face a host of problems in learning the subject matter, which are arguably attributed to the abstract and complicated concepts of the subject. Further compounding such predicament is the pervasive use of the traditional chalk-and-talk approach, which obviously seems out of place in the current educational realm. As such, students tend to lose focus and merely rely on textbook without any concrete supporting materials $[1,2]$. Taking cognizance of the importance of information technology, the use of computer-based tools or applications, notably multimedia learning tools, in the teaching and learning process can surely help improve student learning compared to the traditional approach $[3,4,5]$. Therefore, such use of learning applications must be given strong emphasis by all concerned, in particular by teachers and instructors, to improve the current practice of teaching and learning.

Initially, the researchers carried out an analysis to examine the problems in learning a particular topic of the Form One Mathematics, namely the Integers. The analysis revealed that most students were able to read and write integers, represent such concepts on the graduated line of numbers, and compare values between two integers. However, the same students were observed to be struggling in learning the subtopic that involved sequence of integers, positive and negative numbers, addition and subtraction of integers, operational combination of integers, and problem 
solving of such mathematical operations. Apparently, these findings are consistent with earlier findings of Sopian's [6] study, who found most students were not well conversant with the concept of line numbers, comparison between two integers, and addition and subtraction of integers.

Another study revealed that students exhibited a diverse range of understanding in learning this particular topic of the subject [7], which might have led to some misunderstandings between teachers and students [8]. In addition, Gullick [9] found that learning negative numbers was particularly challenging to students as values of less than zero (which is physically intangible) is a difficult concept to fathom, as they only learned positive numbers in the elementary school. Clearly, this acute lack of understanding might have adversely affected students' ability in learning negative numbers. Moreover, the current practice of teaching and learning using the traditional approach is not helping much in such a predicament. If left unmitigated, students can become unmotivated at best or frustrated at worst.

As such, new approaches should be explored to help students learn such abstract topic more efficaciously especially by using animation. Animation is able to attract attention [10] and provides an overview of abstract processes [11]. Therefore, it is important to produce effective animation. Lasseter [12] states that Walt Disney's animation principles can be used to increase the effectiveness of the animation and many studies suggest that the principle of exaggeration is one of the methods of animation design that can produce interesting animation [13, 14, 15]. In view of the above learning issues, the researchers developed a multimedia learning application that was embedded with the principles of animation exaggeration and to test its effects on students' achievement in the learning of the topic of integers.

To guide the study, two research objectives were formulated. The first objective is to develop a multimedia learning application embedded with the principles of animation exaggeration in helping students to learn the topic of integers of Form One Mathematic. The second objective is to examine the effects of the multimedia learning application embedded with the principles of animation exaggeration on students' learning achievement in the learning of the topic of integers of Form One Mathematic.

\section{LITERATURE REVIEW}

\subsection{Animation}

As universally acknowledged, the Walt Disney was the pioneer in producing digital animations in the 1970s. Today, it is the leader in the world of children animation, having a huge army of animators who creatively develop highly realistic animations. Essentially, the animators create the animation of human's movements based on 12 basic principles of animation, such as squash and stretch, anticipation, staging, straight ahead action and pose to pose animation, follow through and overlapping action, slow in and slow out, arcs, secondary action, timing, exaggeration, weight, and appeal [16].

\subsection{The application of the principles of animation exaggeration}

In this study, the principle of animation exaggeration was utilized to help improve the learning of the topic of integers among students. According to Thomas and Johnston [16], exaggerated animation means that a character that is in a particular psychological state, say sadness, will exhibit extreme sadness than it normally does. Likewise, with exaggerated animation, the same character will look excessively happier than that of the case in which such animation is not used. The principle of exaggeration in animation can be applied to animation through body language, 
squash and stretch and character design. In this study, the principles of animation exaggeration were only applied to certain critical elements of the multimedia application to ensure students would focus on certain concepts of learning. Such elements were movement, facial expression, squash and stretch, bounce, and time interval.

One of the ways to apply the principle of exaggeration in animation is in the construction of the body language. For example if one character has an overweight, the character can be generated using a body language as hard to move. In other example in the Aladdin film [17], emotion of the Magic Carpet is shown through the body language because carpet has no face. The principle of exaggeration is used on the body language to show sad and happy emotional character of the Magic Carpet. Figure 1 shows the happy emotion of the Magic Carpet.

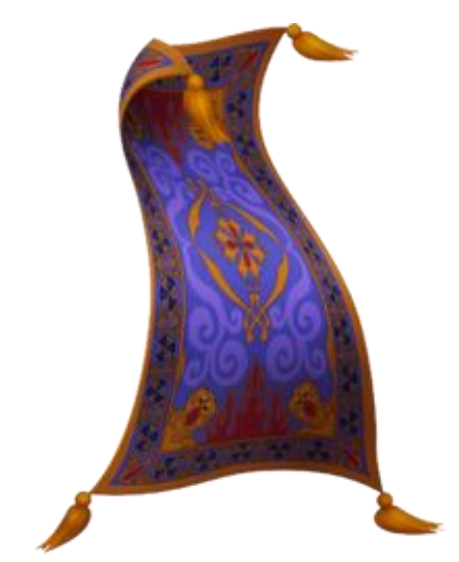

Figure 1. The exaggerated animation of body language

The second way to apply the principle of exaggeration in animation is through squash and stretch. In particular, squash and stretch refers to the impact of force on a moving object. A case in point was the movements of Road Runner in the animated cartoon of Rabid Rider [18], which used exaggerated squash and stretch animation, as shown in Figure 2. The principle of exaggeration in Road Runner animations is used by displaying a long neck and leg behind in the back when Road Runner begins to accelerate which shows its speed and the effect of gravity strength.

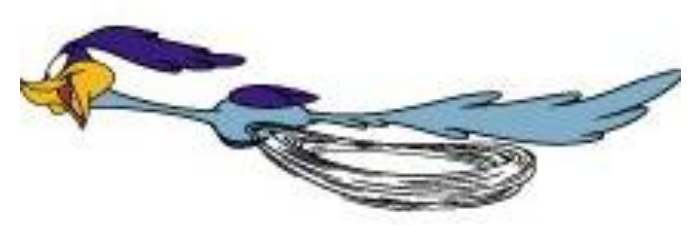

Figure 2. The exaggerated animation of squash and stretch

The third way to apply the principle of exaggeration in animation is in the construction of the character design. The application of such principles in the design of characters can take many forms, such as an excessively overweight man can be modelled as an obese person [19]. Instead of designing an ordinary overweight man, it can be design as an obese as seen in Figure 3. 

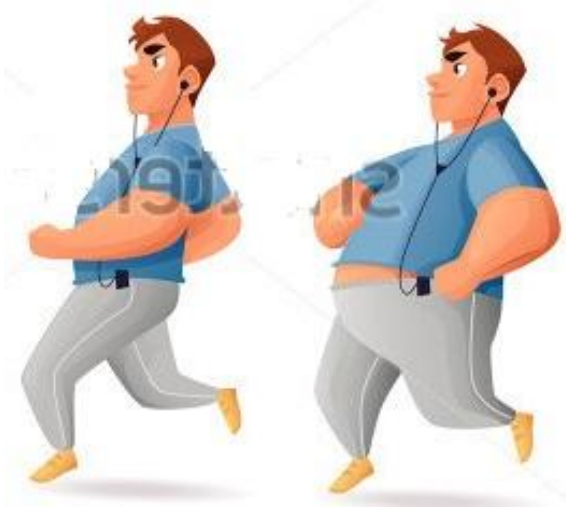

Figure 3. The exaggerated animation of character design

Another interesting example is the popular children cartoon series Upin dan Ipin [20], in which such principles were applied to the Upin's and Ipin's heads, which are the main characters of the series (see Figure 4).

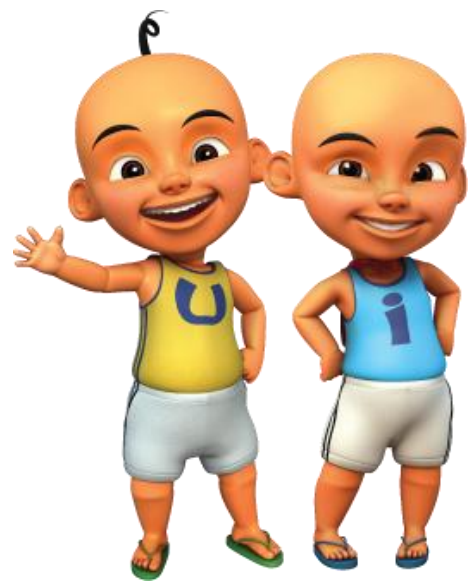

Figure 4. The exaggeration of the main characters of Upin and Ipin

For this study, a combination of two methods of animation exaggeration was used to develop the multimedia learning application based on the requirements of the research, as shown in Figure 5. The two methods of applying the principle of exaggeration that used in the study are squash and stretch and character design.

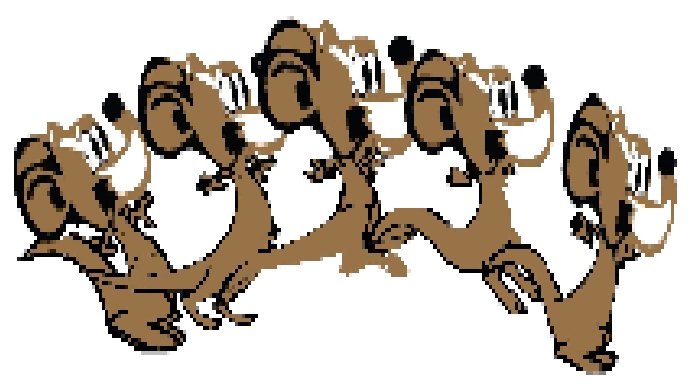

Figure 5. Combination of two method of animation exaggeration

Specifically, the principles of animation exaggeration were applied to the design of a kangaroo to make its head look big from the normal size. Additionally, its movements were manipulated on 
the line number using the squash and stretch method. Such manipulation of exaggerated animations on the line number helped emphasize the learning content of concepts related to the addition and subtraction integers. Figure 6 shows the application of principles of animation exaggeration in the development of the multimedia learning application.

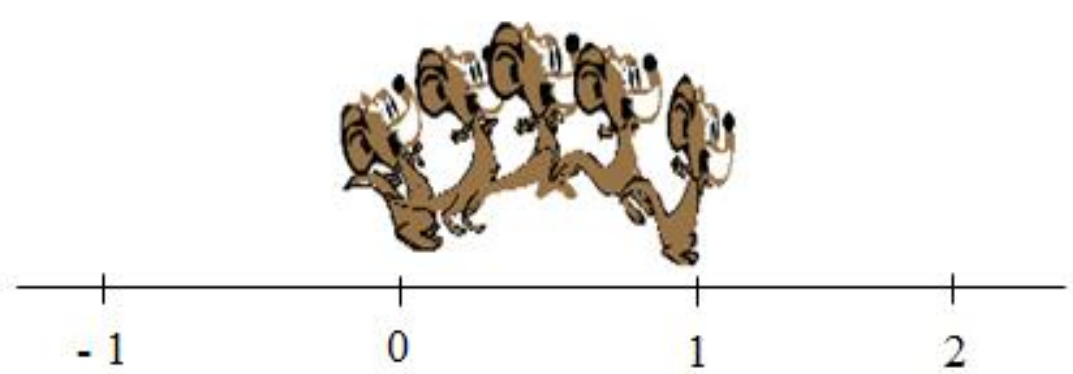

Figure 6. The application of the principles of animation exaggeration

\section{Methodology}

This study was based on the experimental research method involving a multimedia learning application with exaggerated animations with which a group of students used to learn the topic of integers. The researchers used the ADDIE model [21] to develop such application (see Figure 7). Additional data were also collected using the interview method to qualify the research findings.

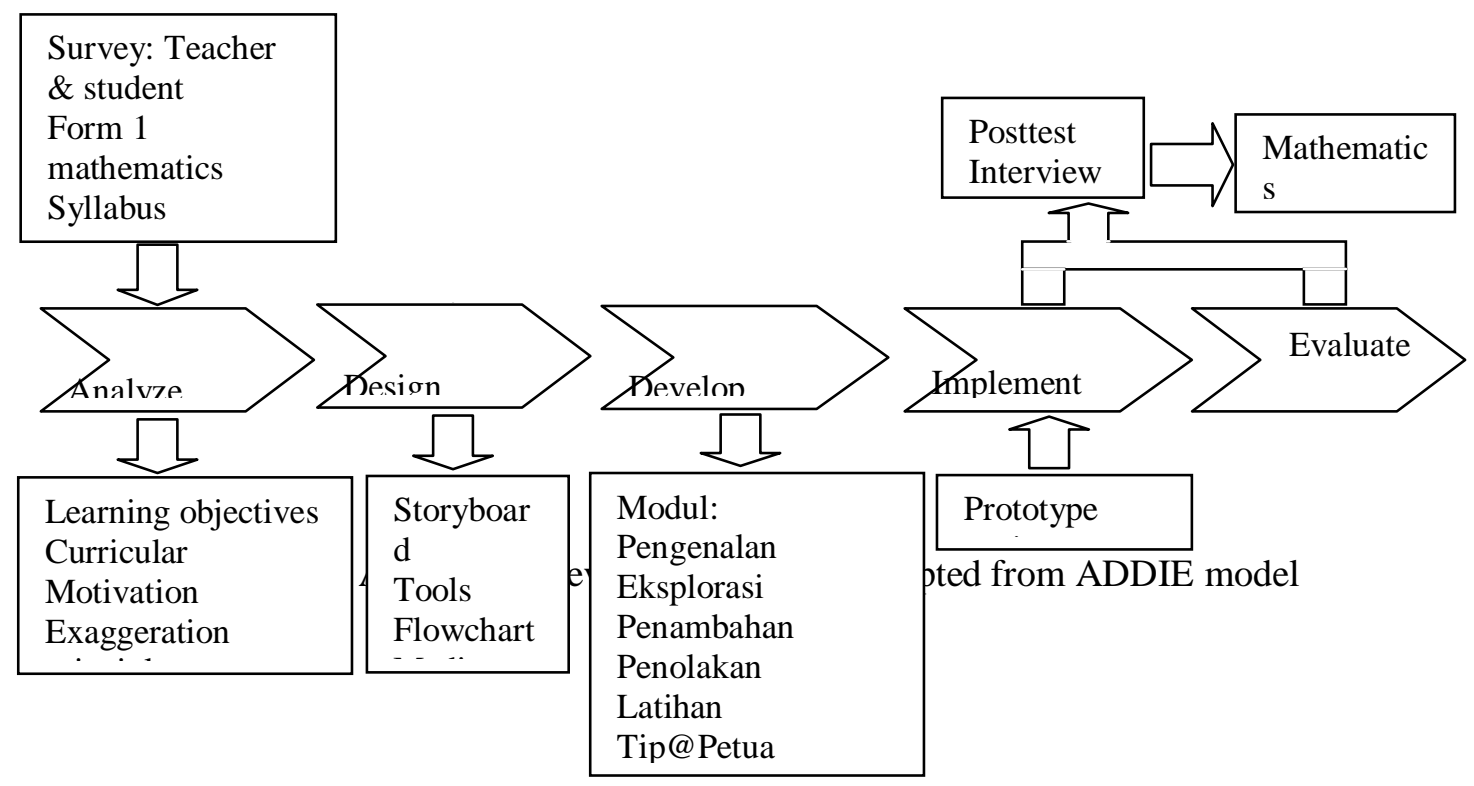

\subsection{Development of the multimedia learning application with principles of animation exaggeration}

In the analysis phase of the ADDIE model, the researchers identified all the requirements for the development of the application. Critical aspects, such as the objectives of learning and teaching, curriculum, student's motivation in computer, and animation principles, were rigorously examined. In particular, the principles of animation exaggeration were emphasized in the development of the application that could help students to learn the topic of integers of the Form 
The International Journal of Multimedia \& Its Applications (IJMA) Vol.9, No.4/5/6, December 2017

One Mathematics more efficaciously. For the analysis of user requirements, the required data were elicited from a survey and an interview involving a group of teacher and students. Such multiple sources of data helped highlight the overall picture of the learning problem prior to developing the application.

The design phase involved the creation of such application with the principles of animation exaggeration. In the application, a kangaroo character was used that would jump along a graduated line of numbers representing a continuum of integers (both positive and negative numbers), as it demonstrated the steps in performing the addition and subtraction of integers (see Figure 8 and Figure 9).

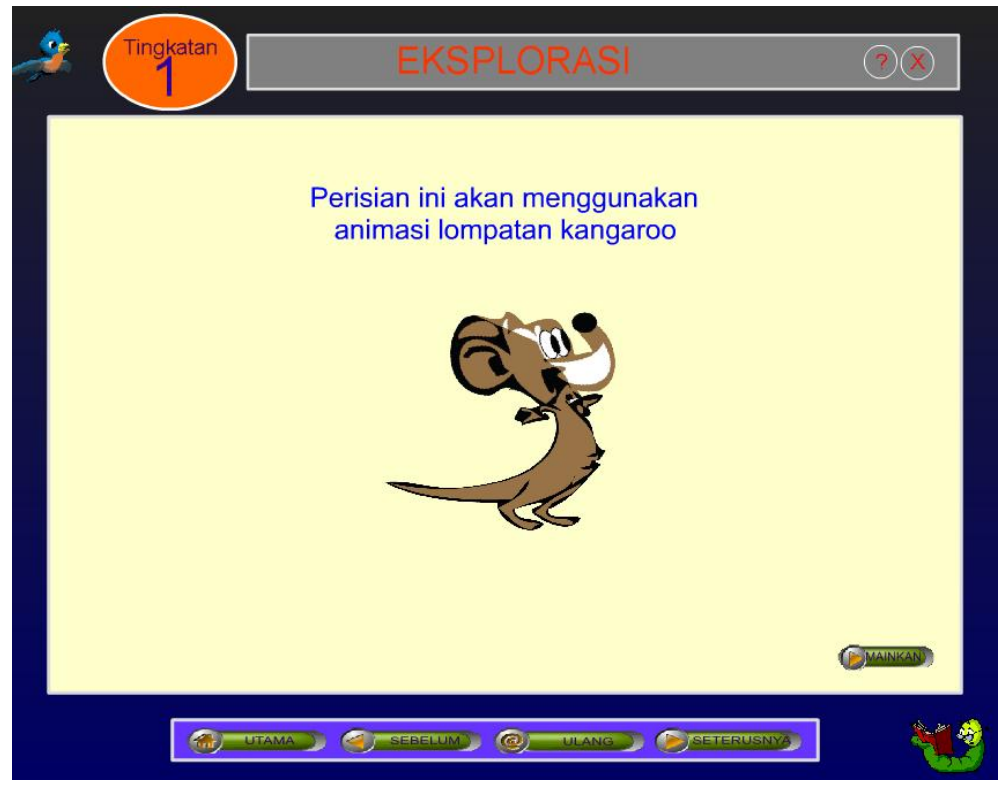

Figure 8 . The main page showing the introduction of the application

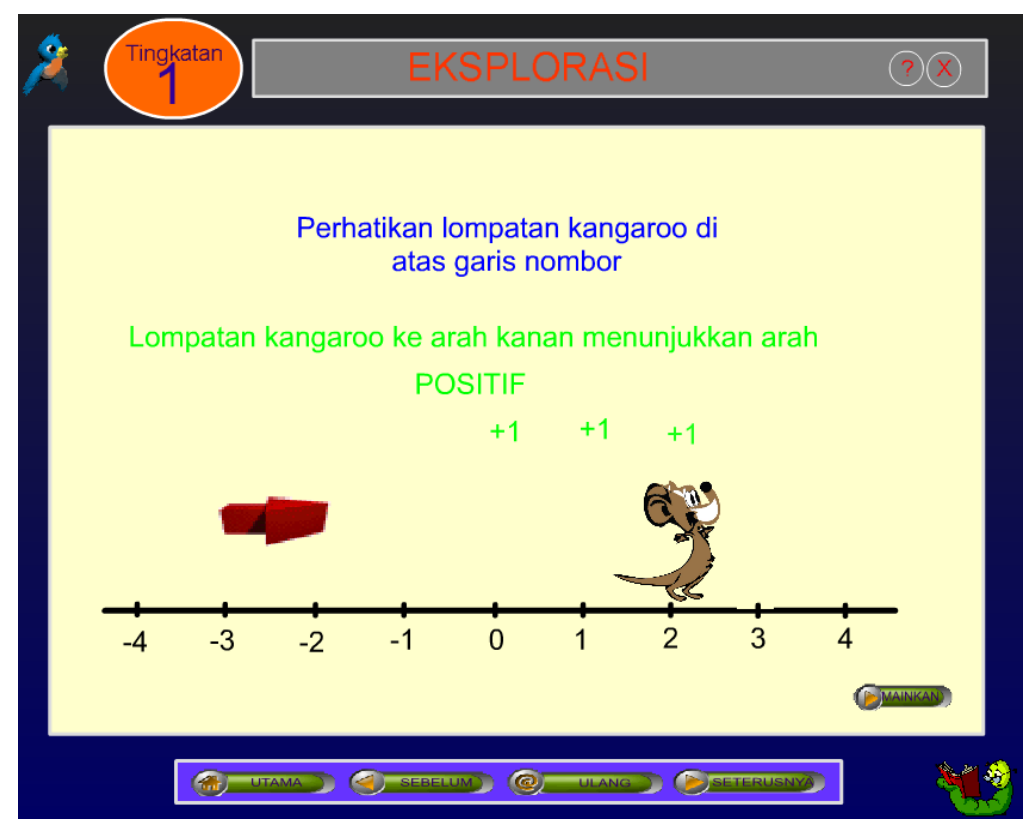

Figure 9. An animation of a positive movement of the kangaroo character 
A prototype of the application to help students learn integers was developed consisting of six modules, namely the introduction, line number animation, addition, subtraction, exercises, and tips and clues. Using the prototype, students would explore the learning modules interactively. Interestingly, in adding or subtracting integers, the kangaroo character with embedded exaggerated animations (see Figure 8) would move along the line number and stop at a particular point that represented the outcome of such mathematical operation (see Figure 9). Such vivid movements of the animated kangaroo would help students to grasp the underlying mechanism in performing the mathematical operations of integers more clearly. For example, the animated kangaroo would jump to the right to represent a positive direction, indicating an addition operation. The opposite was true when it jumped to the left, indicating a subtraction operation of integers.

\subsection{Assessment of the effects of the multimedia application with the principles of animation exaggeration}

In this study, the research design used was the pre-test posttest control group design. Based on the recommendation by Cohen, Manion, and Morrison [22], two experimental groups and one control group were established in this study, which were deemed appropriate for such experimental study that had several levels or categories of variables or factors. All groups took the same test using a similar set of questions prior to treatment (O1), in which they learned the topic of integers. After pretesting, the first experimental group used the multimedia learning application embedded with the principles of animation exaggeration (X1) to learn integers. Slightly differently, the second experimental group used a similar multimedia application with normal animations only (X2) to learn the same mathematical concepts. In contrast, the control group learned the same concept of integers using the conventional method. Table 1 summarizes the pretesting, treatments, and posttesting of the three groups in this study.

Table 1. The pre-test posttest control group design of the study

\begin{tabular}{|l|c|c|c|}
\hline \multicolumn{1}{|c|}{ Group } & Pre-test & Treatment & Posttest \\
\hline Experimental (A) & $\mathrm{O}_{1}$ & $\mathrm{X}_{1}$ & $\mathrm{O}_{2}$ \\
\hline Experimental (B) & $\mathrm{O}_{1}$ & $\mathrm{X}_{2}$ & $\mathrm{O}_{2}$ \\
\hline Control (C) & $\mathrm{O}_{1}$ & - & $\mathrm{O}_{2}$ \\
\hline
\end{tabular}

\section{FINDINGS AND DISCUSSION}

The assessment of the effects of the multimedia application embedded with the principles of animation exaggeration was performed to determine if students made significant gains in their understanding of integers after treatment. Before analysing the posttest data, an analysis on the students' pre-test measurements were carried out to ensure all groups were statistically equivalent in terms of their initial achievements. The analysis showed that the mean scores of such measurements of the first, second, and control group were 27.55, 27.40, and 27.35, respectively, clearly indicating that no three groups differed significantly in their initial understanding of integers.

\subsection{The effects of the multimedia learning application with the principles of animation exaggeration on students' achievement in the learning of integers}

The analysis of variance (i.e., ANOVA) was used to examine the effects of the multimedia application embedded with the principles of animations exaggeration on students' understanding of integers. Specifically, Tukey post hoc test was used to determine which specific groups that 
The International Journal of Multimedia \& Its Applications (IJMA) Vol.9, No.4/5/6, December 2017

had significant differences between them. The analysis showed that there were significant differences in the mean scores of posttest measurements between the experimental and the control group, $\mathrm{F}(2,117)=38.107, \mathrm{p}=.00$., as summarized in Table 3 and Table 4 . The Tukey post hoc test revealed that the first experimental group that had a mean score of $69.78(\mathrm{SD}=15.10)$ differed significantly from the second experimental group that had a mean score of 49.48 ( $\mathrm{SD}=$ 19.20). Likewise, the the first experimental group also differed significantly from the control group, with the latter achieving a mean score of $37.63(\mathrm{SD}=15.40)$ (see Table 2).

Table 2: The descriptive statistics of the posttest measurement

\begin{tabular}{|c|c|c|c|c|c|c|c|c|}
\hline \multicolumn{9}{|c|}{ Descriptive Statistics } \\
\hline \multicolumn{9}{|l|}{ Posttest } \\
\hline & \multirow[b]{2}{*}{$\mathrm{N}$} & \multirow[b]{2}{*}{ Mean } & \multirow[b]{2}{*}{$\begin{array}{l}\text { Standard } \\
\text { Deviation }\end{array}$} & \multirow[b]{2}{*}{$\begin{array}{l}\text { Standard } \\
\text { Error }\end{array}$} & \multicolumn{2}{|c|}{$\begin{array}{l}\text { 95\% Confidence } \\
\text { Interval }\end{array}$} & \multirow[b]{2}{*}{ Minimum } & \multirow[b]{2}{*}{ Maximum } \\
\hline & & & & & $\begin{array}{l}\text { Lower } \\
\text { Bound }\end{array}$ & $\begin{array}{l}\text { Upper } \\
\text { Bound }\end{array}$ & & \\
\hline $\begin{array}{l}\text { Experiment } \\
\text { al } 1\end{array}$ & 40 & 69.78 & 15.056 & 2.381 & 64.96 & 74.59 & 40 & 92 \\
\hline $\begin{array}{l}\text { Experiment } \\
\text { al } 2\end{array}$ & 40 & 49.58 & 19.183 & 3.033 & 43.44 & 55.71 & 17 & 93 \\
\hline Control & 40 & 37.63 & 15.392 & 2.434 & 32.70 & 42.55 & 11 & 76 \\
\hline Total & 120 & 52.33 & 21.215 & 1.937 & 48.49 & 56.16 & 11 & 93 \\
\hline
\end{tabular}

Table 3: Analysis of variance

\begin{tabular}{|c|c|c|c|c|c|}
\hline \multicolumn{7}{|c|}{ ANOVA } \\
\hline Source & $\begin{array}{c}\text { Sum of } \\
\text { Squares }\end{array}$ & $\begin{array}{c}\text { Degree of } \\
\text { freedom }\end{array}$ & $\begin{array}{c}\text { Mean } \\
\text { Square }\end{array}$ & F value & Significance \\
\hline Between group & 21126.200 & 2 & 10563.100 & 38.107 & .000 \\
\hline Within group & 32432.125 & 117 & 277.198 & & \\
\hline Total & 53558.325 & 119 & & & \\
\hline
\end{tabular}

Table 4: Tukey post hoc test

\begin{tabular}{|c|c|c|c|c|c|c|}
\hline \multicolumn{7}{|c|}{ Multiple comparisons } \\
\hline \multicolumn{7}{|c|}{ Posttest Tukey HSD } \\
\hline \multirow{2}{*}{ (I) Group } & \multirow{2}{*}{ (J) Group } & \multirow{2}{*}{$\begin{array}{c}\text { Mean } \\
\text { difference } \\
(I-J)\end{array}$} & \multirow{2}{*}{$\begin{array}{c}\text { Standard } \\
\text { Error }\end{array}$} & \multirow{2}{*}{ Sig. } & \multicolumn{2}{|c|}{ Confidence Interval 95\% } \\
\hline & & & & & Lower Bound & $\begin{array}{l}\text { Upper } \\
\text { Bound }\end{array}$ \\
\hline \multirow{2}{*}{$\begin{array}{l}\text { Experiment } \\
\text { al } 1\end{array}$} & $\begin{array}{l}\text { Experimenta } \\
12\end{array}$ & $20.200^{*}$ & 3.723 & .000 & 11.36 & 29.04 \\
\hline & Control & $32.150^{*}$ & 3.723 & .000 & 23.31 & 40.99 \\
\hline \multirow{2}{*}{$\begin{array}{l}\text { Experiment } \\
\text { al } 2\end{array}$} & $\begin{array}{l}\text { Experimenta } \\
11\end{array}$ & $-20.200^{*}$ & 3.723 & .000 & -29.04 & -11.36 \\
\hline & Control & $11.950^{*}$ & 3.723 & .005 & 3.11 & 20.79 \\
\hline \multirow{2}{*}{ Control } & $\begin{array}{l}\text { Experimenta } \\
11\end{array}$ & $-32.150^{*}$ & 3.723 & .000 & -40.99 & -23.31 \\
\hline & $\begin{array}{l}\text { Experimenta } \\
12\end{array}$ & $-11.950^{*}$ & 3.723 & .005 & -20.79 & -3.11 \\
\hline
\end{tabular}


In general, students of the first experimental group were significantly superior compared to those in the second experimental group and the control group. Thus, this finding suggests that the principles of animation exaggeration can help improve the learning of integers of Form One Mathematic. Additionally, during the interview session, the students indicated that they found the animations to be very helpful in assisting them to learn integers. Thus, this finding effectively qualifies the above finding by adding more credence to such contention. A majority of all the students reported that the use of graphics and animations in the learning activities was not only helpful but also entertaining to a certain extent, especially the animated kangaroo that helped them to clearly see and learn the steps in the addition and subtraction of integers. The movements of the kangaroo character and the positions at which it stopped showed them the correct steps of the mathematical operations of integers.

Indeed, a positive comment received from one of the student about animation based on the principle of exaggeration produced: "The movements of the exaggerated kangaroo on the number line are interesting and it's easier for me to understand the operations of addition and subtraction of integers".

Another student also illustrates his view: "I enjoyed watching the kangaroo jump on the number line. It is easy to understand the integer operation because I can see the exaggerated animation kangaroo movement on the number line".

Evidently, using the multimedia learning application with the principles of animation exaggeration enabled them to become more attentive and remain focused in learning the concepts of integers. More importantly, the application of the principles of animation exaggeration helped emphasize the proper mathematical operations of integers that students had to learn, the impact of which they could better understand the concept of integers and apply it appropriately in relevant mathematical contexts. Equally important was that the use of the learning tool with exaggerated animations helped highlight students' common mistakes or misconceptions of this particular topic of the Form One Mathematics. Hence, similar mistakes or misconceptions were avoided as they continued to learn such a topic. Ultimately, with higher engagement and zest, the students managed to enhance their understanding of the topic, which was made evident by their significant improvement after the treatment. In fact, this finding is consistent with the research finding of Gielniak and Andrea [14], who found the research subjects that used exaggerated animations were able to answer the test questions more correctly than those without such animations.

\section{CONCLUSiON}

This experimental research was carried out to examine the impact of the application of the principles of animation exaggeration on students' understanding of the topic of integers of Form One Mathematics. The analysis performed on the experimental data showed that the group that used the multimedia learning tool embedded with the principles of animation exaggeration attained significantly higher learning achievement compared to those who learned with similar learning tool with normal animations and to those who learned conventionally. Clearly, such principles had significant and positive effect on students' learning achievement in this particular topic. Furthermore, the feedback from the interview qualitatively supported such finding, indicating that students viewed the multimedia learning tool embedded with exaggerated animations to be extremely useful. Given these promising findings, the principles of animation exaggeration can be harnessed in the development of new multimedia learning applications to help students learn more efficaciously in various school subjects, notably in subjects with complicated, abstract concepts. 
The International Journal of Multimedia \& Its Applications (IJMA) Vol.9, No.4/5/6, December 2017

\section{ACKNOWLEDGEMENTS}

The authors would like to thank everyone who provided insight and expertise that greatly assisted the research. All the forms of guidance and support given are very much appreciated.

\section{REFERENCES}

[1] Mantzicopoulos, P. \& Patrick, H. (2010). "The seesaw is a machine that goes up and down: Young children's narrative responses to science-related informational text." Early Education and Development, (21), 412-444.

[2] Mantzicopoulos, P., \& Patrick, H. (2011). "Reading picture books and learning Science: Engaging young children with informational text". Theory Into Practice 50(4),269-276.

[3] Riaza Mohd Rias \& Halimah Badioze Zaman, (2009). "Using 3-D animation in multimedia learning for memory management concepts". Proceedings of the International Conference on Signal ProcessingSystems, Singapore. 748-753.

[4] Yin Xiaoteng (2015). "A study of the effect of multimedia courseware on oral college English teaching". Journal of Language Teaching and Research, 6(5), 1106-1114. DOI: http://dx.doi.org/10.17507/jltr.0605.25.

[5] Tong Pang (2015). "Research on the applications of multimedia technique in the mathematical teaching and education", International Conference on Economy, Management and Education Technology.

[6] Sopian M. (2011). "Masalah pembelajaran Matematik di kalangan pelajar tingkatan satu dalam tajuk integer". Tesis Sarjana Muda. Universiti Teknologi Malaysia.

[7] Naylor, M. (2007). "More fun with algorithms. teaching K-8". Proquest Education Journal 37(8), 3840.

[8] Brumbaugh, K., \& Rock, D. (2006). Teaching secondary Mathematics. (3rd edition). Lawrence Erlbaum Assosiates:New Jersey.

[9] Gullick, M. M. (2012). "Understanding less than nothing: Investigations into the representation of negative numbers". Doctoral dissertation, Dartmouth College. Hanover, New Hampshire.

[10] Korakakis, G., Pavlatou, E. A., Palyvos, J. A., \& Spyrellis, N. (2009). "3D visualization types in multimedia applications for science learning: A case study for 8th grade students in Greece". Computers \& Education, 52(2), 390-401.

[11] Zeena, A. S., \& Karim, Q. H. (2016). "3D Simulation system for physical lab using an object oriented approach".. International Journal of Computer Applications, 143(1).

[12]Lasseter, J. (1987). "Principles of traditional animation applied to 3D computer animation". ACM Computer Graphics, 21(4), 35-44.

[13] Minghua, L., \& Ping, W. (2010). "Study on image design in animation". Asian Social Science, 39-43.

[14] Gielniak M. J. \& Andrea L. T. (2012). "Enhancing interaction through exaggerated motion synthesis". 7th ACM/IEEE International Conference on Human-Robot Interaction (HRI).

[15] Kolokouri, E., \& Plakitsi, K. (2016). "A CHAT approach of light and colors in Science teaching for the early grades". World Journal of Education, 6(4).

[16]Thomas F., \& Johnston O. (1995). "The illusion of life: Disney animation". Walt Disney Production:USA.

[17]Aladdin (1992). [Film]. Directed by Clement, R., \& Musker, J. USA: Disney.

[18] Rabid Rider (2010). [Film] Directed by Matthew O., Warner Bros.

[19] Hedgpet K. \& Missal S. (2003). "Exploring drawing for animation: The art and technique for drawing for 2D animation." Illustrated Ed. Cengage Learning.

[20] Upin \& Ipin. (2015). [Film] Directed by Adam Amiruddin. Les' Copaque Production.

[21]Branson, R. K., Rayner, G. T., Cox, J. L., Furman, J. P., King, F. J., \& Hannum, W. H. (1975). "Inter service procedures for instructional systems development". 5.

[22] Cohen L., Manion L., \& Morrison K. (2011). Research method in education (7th edition). New York: Routledge. 


\section{Authors}

Dr. Nor Hasbiah Ubaidullah is working as an Associate Professor at Universiti Pendidikan Sultan Idris. She received degree in Computer Science from Universiti Kebangsaan Malaysia and master of Science in Information System from University of Salford. She obtained her $\mathrm{PhD}$ degree in Information Te chnology from Universiti K ebangsaan Malaysia.Her research areas include Courseware Engineering, DSS, Learning Disability Children, Systems/ Product Development, Programming C++ and JAVA.

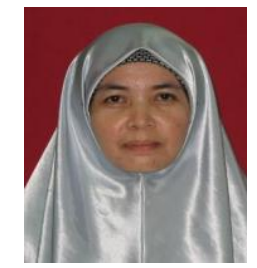

Aizu Khalili Zohedi has degree in Computer Science from Universiti Sains Malaysia and master in Education from Universiti Pendidikan Sultan Idris. His research interest includes Multimedia and Programming C++.

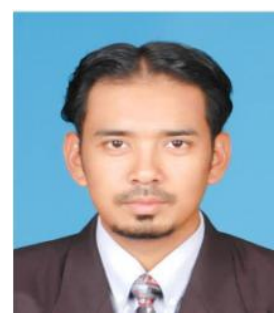

Dr. Norasikin Fabil is working as a Senior Lecturer at Universiti Sains Islam Malaysia. She received degree in Information Technology from Universiti Utara Malaysia and master of Information Technology from Universiti Kebangsaan Malaysia. She obtained her $\mathrm{PhD}$ degree in Information Science from Universiti Kebangsaan Malaysia. Her research areas include Information Visualization, Multimedia, ID and HCI. 